\title{
Respiratory viruses in children younger than five years old with acute respiratory disease from 2001 to 2004 in Uberlândia, MG, Brazil
}

\author{
LF Costa, J Yokosawa*, O C Mantese**, TFM O liveira, HL Silveira**, LL Nepomuceno, \\ LS Moreira, G Dyonisio, LMG Rossi, RC O liveira, LZG Ribeiro, DAO Q ueiróz/+
}

Laboratório de Virologia, Instituto de Ciências Biomédicas, Universidade Federal de Uberlândia, Av. Pará 1720, Bloco 4C, 38400902 Uberlândia, MG, Brasil *NG Biotecnologia Ltda., São Paulo, SP, Brasil **Hospital de Clínicas, UFU,

Uberlândia, MG, Brasil

The main viruses involved in acute respiratory diseases among children are: respiratory syncytial virus (RSV), influenzavirus (FLU), parainfluenzavirus (PIV), adenovirus (AdV), human rhinovirus (HRV), and the human metapneumovirus (hMPV). The purpose of the present study was to identify respiratory viruses that affected children younger than five years old in Uberlândia, Midwestern Brazil. Nasopharyngeal aspirates from 379 children attended at Hospital de Clínicas (HC/UFU), from 2001 to 2004, with acute respiratory disease, were collected and tested by immunofluorescence assay (IFA) to detect RSV, FLU A and B, PIV 1,2, and 3 and AdV, and RT-PCR to detect HRV. RSV was detected in 26.4\% (100/379) of samples, FLU A and B in 9.5\% (36/379), PIV 1, 2 and 3 in 6.3\% (24/ $379)$ and $A d V$ in $3.7 \%$ (14/379). HRV were detected in $29.6 \%$ (112/379) of the negative and indeterminate samples tested by IFI. RSV, particularly among children less than six months of life, and HRV cases showed highest incidence. Negative samples by both IFA and RT-PCR might reflect the presence of other pathogens, such as hMPV, coronavirus, and bacteria. Laboratorial diagnosis constituted an essential instrument to determine the incidence of the most common viruses in respiratory infections among children in this region.

Key words: respiratory viruses - respiratory disease - immunofluorescence assay - reverse transcription of polymerase chain reaction - children

Viruses are the most frequent agents that cause acute respiratory infections (ARIs) and are responsible for a considerable percentage of childhood mortality (Williams et al. 2002). In Brazil, some reports from different geographical areas has revealed the viruses as the main cause of respiratory infections, as related in the cities of Fortaleza (Arruda et al. 1991), Rio de Janeiro (Nascimento et al. 1991), São Paulo (Miyao et al. 1999, Vieira et al. 2001), and Curitiba (Tsuchiya et al. 2005).

The most important viruses involved in ARI are: respiratory syncytial virus (RSV), influenzaviruses types A and B (FLU A/B), parainfluenzavirus (PIV), adenovirus (AdV), human rhinovirus (HRV), and the human metapneumovirus (hMPV) (Miyao et al. 1999, Kuiken et al. 2003, Tsuchiya et al. 2005). The last one was recently identified by Hoogen et al. (2001).

$\mathrm{RSV}$ is the main cause of viral lower respiratory tract illness in children (Miyao et al. 1999), particularly in those younger than six months old (mo.) (Queiróz et al. 2002, Moura et al. 2003). In addition, RSV infections are responsible for most cases of severe symptoms such as bronchiolitis with recurrent wheezing and pneumonia (Calegari et

Financial support: Fapemig, CNPq, UFU

LF Costa was sponsored by Capes.

+Corresponding author: dqueiroz@icbim.ufu.br

Received 3 January 2006

Accepted 27 April 2006 al. 2005) and for leading to a high number of hospitalizations (Tsuchiya et al. 2005).

FLU is a serious public health problem worldwide, were children constitute the age group most affected (Neuzil et al. 2002). Although many infections caused by FLU could be prevented by effective vaccination program, it has been predicted that a pandemic is likely to emerge in a near future (Cox et al. 2003), caused by a virus variant not covered by the current vaccine, requiring, thus, a constant epidemiological surveillance.

PIV seems to have pattern of seasonal occurrence and is considered an important cause of respiratory illnesses, particularly among young children (Monto 2002).

$\mathrm{AdV}$ infections are common in all age groups, causing both hospital- and community-acquired epidemics. Moreover, AdV has been associated with hospitalizations of near-fatal asthma patients (Tan et al. 2003) and with cases of acute otitis media in children younger than two years old (Monobe et al. 2003).

HRV is responsible for the majority of common colds during winter, causing upper respiratory infections (Arruda et al. 1991, Savolainen et al. 2003) and is considered a risk factor for acute otitis media (Monobe at al. 2003). In addition, HRV accounts for serious lower respiratory illness in infants and children with bronchopulmonary dysplasia (Kotaniemi-Syrjänen et al. 2003) and contributes for asthma exacerbations (Monto et al. 2001).

Some host factors, such as age, have been shown relevant for increasing the incidence and/or severity of respiratory infections caused by viruses in both children and elderly people (Zamorano et al. 2003). In the present 
study, our main objective was to determine what respiratory viruses are the causative agents of acute respiratory disease in young children in Uberlândia city, Midwestern Brazil, located in a region characterized by dry winters, rainy summers, and mild variations of temperatures.

\section{MATERIALS AND METHODS}

Samples - Three hundred and seventy nine samples of children younger than five years old who participated in this study were collected from 2001 to 2004. Children with acute respiratory infection were attended at Hospital de Clínicas of the Universidade Federal de Uberlândia (HC/ UFU) and the samples were collected within five days of the onset of the symptoms in the following hospital units: (i) first aid (FA), (ii) pediatric first aid (PFA), (iii) pediatric ward (PW), (vi) pediatric intensive care unit (PICU), and v) neonatal intensive care unit (NICU). Demographic data, such as age, gender, and clinical symptoms were also obtained at the moment of the sample collection. Nasopharyngeal aspirates (NPAs) were collected according to Calegari et al. (2005), by instillation of $0.5 \mathrm{ml}$ of buffered solution $(0.9 \%)$ into the nostrils of a patient followed by aspiration by a vacuum system using a catheter. Samples were transported on ice to the Laboratório de Virologia and processed as previously described (Queiroz et al. 2002). This study was approved by the Ethics Committee of UFU according to resolution no. 196/1996/CNS. Written consent was obtained from the children's parents.

Indirect immunofluorescence assay (IFA) - The assay was carried out by using the Respiratory Panel I Viral Screening and Identification Kit (Chemicon International, Inc., Temecula, CA), following the manufacturer's instructions, for detection of the following respiratory viruses: RSV, FLU A/B, PIV 1, 2, and 3), and AdV.

Reverse transcription-polymerase chain reaction (RT$P C R$ ) for detection of HRV - The assay was applied to detect HRV RNA sequence in samples that were negative or indeterminate by IFA. Total RNA was extracted with Trizol (Invitrogen Corporation, Carlsbad, CA), following the manufacturer's instructions. Complementary DNA (cDNA) synthesis and PCR amplification conditions were described by Arruda and Hayden (1993). The only modification we made was that primer 1 , which was used for cDNA synthesis, was also added in the first-round PCR mixture, however maintaining the final primer concentration described by these authors. HRV grown in cell culture was a gift from Dr E Arruda (Faculdade de Medicina de Ribeirão Preto, Universidade de São Paulo) and was used as positive control.

Statistical analysis - Statistical analysis were carried out by using BioEstat version 3.0 (Ayres et al. 2003). Differences between proportions were evaluated by Quisquare test. Incidence of the referred respiratory viruses and the respective confidence intervals (CI) of 95\% were calculated; $p$ values lower than 0.05 were considered statistically significant.

\section{RESULTS}

From 2001 to 2004, 379 nasopharyngeal specimens of children younger than five years old with acute respira- tory disease were tested by IFA for RSV, FLU A/B, PIV 1, 2 and 3 , and AdV. Samples that were negative or indeterminate by IFA were tested by RT-PCR for detection of HRV.

Approximately 75\% (286/379) of all samples were positive for the presence of any of these viruses (Table I). HRV cases responded for $29.6 \%$ (112/379), followed by RSV cases (26.4\% - 100/379), FLU (9.5\% - 36/379), PIV (6.3\% - 24/379), and AdV (3.7\% - 14/379), whereas samples which showed results that were either negative or indeterminate for those viruses tested responded for $24.6 \%$ (Fig. 1).

\section{TABLE I}

Age distribution of the positive cases by indirect immunofluorescence and reverse transcription-polymerase chain reaction assays from 2001 to 2004, in Uberlândia, MG

\begin{tabular}{lrrrrrr}
\hline $\begin{array}{l}\text { Age in } \\
\text { months }\end{array}$ & RSV & FLU & PIV & AdV & HRV & Total \\
\hline$<3$ & 37 & 2 & 1 & 1 & 19 & 60 \\
$3-6$ & 15 & 5 & 2 & 1 & 18 & 41 \\
$6-9$ & 12 & 3 & 2 & 2 & 13 & 32 \\
$9-12$ & 5 & 2 & 3 & 3 & 13 & 26 \\
$12-24$ & 20 & 15 & 7 & 6 & 25 & 73 \\
$\geq 24$ & 11 & 9 & 9 & 1 & 24 & 54 \\
\hline Total & 100 & 36 & 24 & 14 & 112 & 286 \\
\hline
\end{tabular}

RSV: respiratory syncytial virus; FLU: influenzavirus; PIV: parainfluenza virus; AdV: adenovirus; HRV: human rhinovirus.

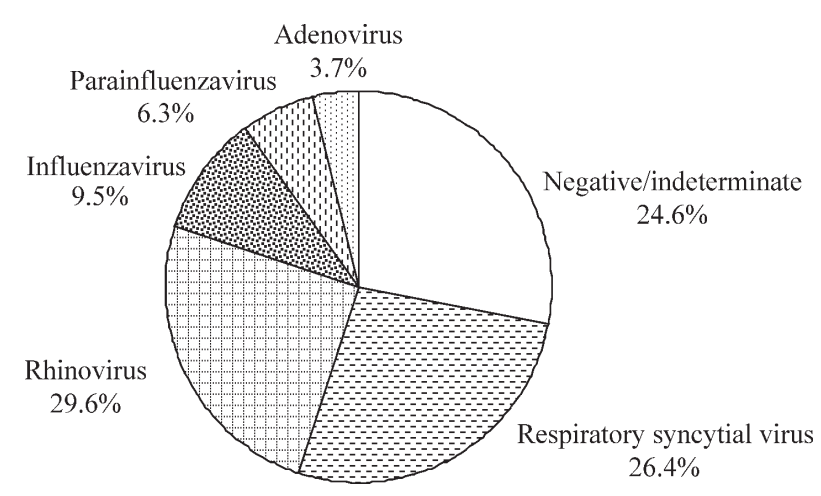

Fig. 1: percentage distribution of the results evaluated by indirect immunofluorescence assay and reverse transcription-polymerase chain reaction.

It was observed a significant difference among the total proportions of the cases along the age groups $(p<$ 0.05 ). This difference was also observed to RSV cases according to age distribution $(p=0.00)$, in which the age group corresponding to children younger than three mo. was more affected $(37 / 100)$ than the other age groups: 3-6 mo. $(p=0.00), 6-9$ mo. $(p=0.00), 9-12$ mo. $(p=0.00), 12-$ $24(p=0.03)$, and $\geq 24$ mo. $(p=0.00)$. For HRV, no significant difference was found in the distribution of cases according to age group $(p>0.05)$. 
Regarding nosology, the most common symptoms related to HRV, FLU, PIV, and AdV infections were those involving the upper respiratory tract, mostly in children older than one year old (Table II). On the other hand, RSV infections were related mostly to bronchiolitis and pneumonia/bronchopneumonia cases (lower respiratory tract), especially in children younger than six mo. $(p<0.05)$, responding for 60 and $46 \%$ of the cases, respectively. HRV were detected in $25 \%$ of bronchiolitits cases in children less than six mo. and in $15.4 \%$ of pneumonia/bronchopneumonia cases at the same age group. For influenzaviruses, almost 2/3 (26/36) of the FLU infections, involved the upper respiratory tract, whereas the lower respiratory tract disease responded for $11.1 \%$ (4/36).

Regarding seasonality, the outbreaks occurred mainly during the months with low temperatures of Uberlândia (Fig. 2). RSV cases were detected from February to Junelate summer to late autumn in this region, with highest incidence from April to May, revealing a clear seasonality.
Peak of FLU cases occurred shortly after, in mid-winter, and extended to the end of the season. PIV and AdV cases did not show a clear seasonality, although these viruses were detected during the coldest rather than the hottest months. Similar data were observed for HRV, having, however, a peak of incidence during the coldest months, mostly in June with $28 \%$ (31/112) of the cases.

\section{DISCUSSION}

The application of IFA and RT-PCR allowed us to detect a viral agent in 75.5\% (286/379) of the nasopharyngeal specimens of children under five years of age with acute respiratory disease. In Brazil, Souza et al. (2003), in order to determine the incidence of viral respiratory infectious episodes in young children detected a viral agent in $42.8 \%$ of the samples by using IFA. Yet, Tsuchyia et al. (2005) identified a viral agent in 30\% of the nasopharyngeal aspirate or bronchoalveolar lavages samples tested using shell vial culture and IFA.

TABLE II

Main nosological diagnostic of the respiratory infections according to age and to etiological agent

\begin{tabular}{|c|c|c|c|c|c|c|c|c|c|c|c|c|c|c|c|}
\hline \multirow{2}{*}{$\begin{array}{l}\text { Symptoms } \\
\text { Age in } \\
\text { months }\end{array}$} & \multicolumn{5}{|c|}{ Bronchiolitis } & \multicolumn{5}{|c|}{ Pneumonia/BCP } & \multicolumn{5}{|c|}{ URTI } \\
\hline & HRV & RSV & FLU & PIV & AdV & HRV & RSV & FLU & PIV & AdV & HRV & RSV & FLU & PIV & AdV \\
\hline$<3$ & 6 & 22 & - & 1 & - & 2 & 6 & - & - & 1 & 3 & 7 & 1 & - & - \\
\hline $3 \neg 6$ & 12 & 7 & 1 & - & - & 2 & 3 & 2 & - & - & 6 & 3 & 2 & 2 & 1 \\
\hline 9ר6 & 2 & 7 & - & - & - & - & - & - & - & 1 & 8 & 2 & 2 & 2 & 1 \\
\hline 12 12 & 2 & 4 & - & - & 2 & 2 & - & - & - & - & 4 & 1 & 2 & 1 & 1 \\
\hline $12 \neg 24$ & 1 & 2 & 1 & - & 1 & 3 & 2 & - & 1 & - & 15 & 10 & 12 & 5 & 4 \\
\hline$\geq 24$ & 1 & 2 & 1 & - & 1 & 3 & 2 & - & 1 & - & 15 & 10 & 12 & 5 & 4 \\
\hline Total & 23 & 43 & 2 & 1 & 3 & 9 & 12 & 2 & 1 & 2 & 49 & 29 & 26 & 14 & 8 \\
\hline
\end{tabular}

URTI: include flu, cold, and acute otitis media; HRV: human rhinovirus; RSV: respiratory syncytial virus; FLU: influenzavirus; PIV: parainfluenzavirus; AdV: adenovirus

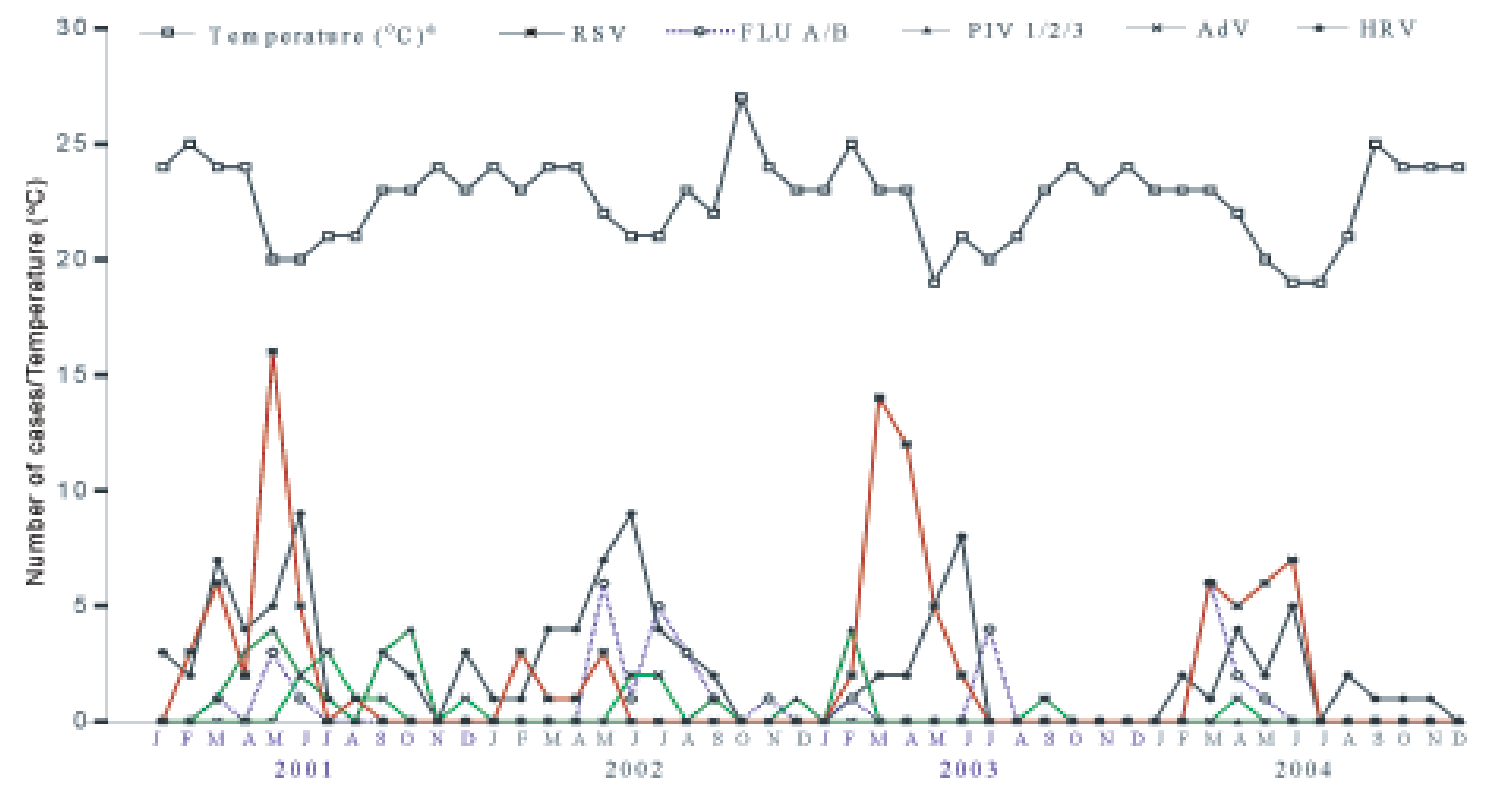

Fig. 2: monthly incidence of the respiratory virus among children up to five years old by immunofluorescence and reverse transcriptionpolymerase chain reaction methods from January 2001 to December 2004, in Uberlândia, MG; $a$ : data from Laboratório de Climatologia e Recursos Hídricos/Universidade Federal de Uberlândia. 
Moreover, Monobe et al. (2003) using multiplex nested RT-PCR from middle ear fluid of children with acute otitis media, identified a virus in $42 \%$ of the specimens. Finally, Tan et al. (2003) revealed that a viral agent was found in $52 \%$ of patients with near fatal asthma, asthma or chronic pulmonary disease, using PCR. Thus, the present study reveals the importance of applying at least two methods in order to improve the identification of respiratory pathogens.

The detection of RSV by IFA in approximately one fourth of the samples, demonstrated that this virus is a frequent agent of respiratory disease in children, particularly for those in their first six mo. of age. Some reports have shown that the RSV is a frequent cause of acute respiratory infections in children younger than five years old, with incidence reaching 17\% (Moura et al. 2003), 18\% (Bosso et al. 2003), 22\% (Cintra et al. 2001), and 28\% (Checon et al. 2002) of the investigated cases.

The finding that RSV infections were mainly associated with bronchiolitis and pneumonia/bronchopneumonia (60 and $46 \%$ of the cases, respectively), demonstrated that this agent was an important cause of lower respiratory tract infections, results that were also found by Nascimento et al. (1991), Vieira et al. (2001), Moura et al. (2003), and Tsuchiya et al. (2005). Moreover, the fact that approximately half of RSV infections (52/100) occurred in children under 6 mo., showed that patients in this age group are the most vulnerable to infections caused by RSV, despite the presence of maternal antibodies (Queiróz et al. 2002). Also in the same age group, severity of the infection caused by RSV was observed in those patients that presented bronchiolitis and pneumonia/bronchopneumonia ( 40.3 and $34.6 \%$, respectively).

The frequency and severity of RSV infections in this age group seem to be a consequence of complex and multifactorial events, involving especially immunological factors (Queiróz et al. 2002). In spite of the fact that infants are relatively immature in their ability to mount immune response to respiratory virus infections, maternal antibodies are an important means of protection (Crowe 2001). Although Glezen et al. (1981) suggested that infants with high levels of maternal RSV-neutralizing antibodies developed mild illness, lactates and young children are the groups most affected by RSV (Queiróz et al. 2002, Checon et al. 2002, Moura et al. 2003, Bosso et al. 2004). Also, it still remains unclear whether the severity of RSV infection could be triggered by cross-reactivity between RSV subtype-specific maternal antibodies and a different RSV variant.

Anatomic restrictions of the neonatal bronchial tree could also explain the severity in neonatal and young infants infected with RSV, mediated by hyper reactivity of substance $\mathrm{P}$ and its receptor NK1 on target cells early in infancy than later in life (Piedimonte 2001). Also, according to the hygiene hypothesis (Benten et al. 2005), repeated respiratory infections could induce immune maturation in children, decreasing the incidence and the severity of respiratory diseases.

Results obtained for FLU, PIV, and AdV cases in other age groups of this study are in agreement with Erhart et al. (2004). In these cases, maternal antibodies could prob- ably provide an important mechanism of protection in young children (Crowe 2001).

The detection of influenzaviruses in $9.5 \%$ of the cases indicated that this agent is an important cause of respiratory disease among children (Heikkinen et al. 2004), similar to related by Neuzil et al. (2002). However, the number of FLU positive samples might be increased by using PCR based methods (Ellis \& Zambon 2002). Regarding the nosology, 2/3 of FLU cases were related to upper respiratory tract infections, whereas the lower respiratory tract disease were observed in $11.1 \%$ of the cases. However, it is important to be aware about the emergence of pandemic strains that has been emerging along the years, such as H5N1 (Barrera \& Reyes-Terán 2005).

Detection of HRV in $29.6 \%$ of the cases demonstrated that this virus is not only a common agent of respiratory infections in adults, but it is also frequently detected in children, as previously reported (Arruda et al. 1991, Savolainen et al. 2003). Although most of HRV cases occurred in patients with upper respiratory tract disease, as reported by Heikkinen and Jãrvinen (2003), the virus was also detected in $25 \%$ of bronchiolitis and in $15.4 \%$ of pneumonia/bronchopneumonia cases in children younger than six mo., indicating that HRV was probably involved with more severe symptoms of lower respiratory tract. Similar results were reported by Papadopoulos et al. (2002) and by Hayden (2004). However, co-infection with other pathogens, which might enhance the severity of the HRV-related diseases, can not be discarded (Malcolm et al. 2001). Moreover, atopic diseases (not evaluated here) and young age could also be enhancing the disease severity by HRV (Lemanske et al. 2005).

Regarding gender (results not shown) male children were more frequently affected by respiratory viruses than females, in agreement to studies reported by Monto (2002).

In general, respiratory viruses were detected mostly during the coldest and driest months of Uberlândia, which has a semitropical climate, characterized by an interchange of dry and mildly cold winters and rainy summers. Circulation of the respiratory viruses shows different patterns, according to the region. In tropical regions, such as Salvador, in Northeastern Brazil (Moura et al. 2003), respiratory viruses were detected mostly in rainy seasons, whereas in subtropical regions, as São Paulo, in Southeastern Brazil (Vieira et al. 2001) and Porto Alegre, in Southern Brazil (Strallioto et al. 2001), they were mainly detected during the coldest months, as similarly found in Uberlândia, which however has a short time period with low temperatures.

In this study, RSV was detected from February to June (late summer to late autumn), with peak in April and May (autumn), as similarly related in Ribeirão Preto (SP) by Cintra et al. (2001) and in Vitória (ES) by Checon et al. (2002), and has not been detected in other months. In regions with lower temperatures during winter, such as São Paulo (Vieira et al. 2001), Botucatu (Bosso et al. 2004), and Porto Alegre (Strallioto et al. 2001) cities, RSV circulation extended to July or August (mid-winter). Thus, it seems that RSV circulation accompanies low temperatures. Moreover, RSV circulation showed, in our study, an alternate pattern of incidence. In 2001 and 2003, there were 
more RSV cases in comparison to 2002 and 2004. This is apparently related to the lower temperatures registered in Uberlândia in 2001 and 2003.

The detection of FLU from March to August, with peak in May, suggests that this virus is also more frequently related to the coldest months of the year, which is in accordance to data reported by Monto (2002). Similarly, HRV was mainly detected during the months with lower temperatures in Uberlândia and is in agreement with results reported by Monto (2002). PIV and AdV showed no apparent regular seasonal pattern. For AdV, similar data was reported by Souza et al. (2003).

Additional studies are needed in order to elucidate the etiology in those cases that showed either negative or indeterminate results, which might indicate the presence of other pathogens, such as human metapneumovirus, coronavirus or bacteria. hMPV is considered an important pathogen that causes respiratory infections in children younger than five years old (Kuiken et al. 2003). Difficulties related to the methodology, such as infection time point of sample collection or the sample collection procedure itself might also have been the cause of these results.

Laboratorial investigation has proved to be necessary for viral identification in acute respiratory disease among children of Uberlândia region. However, continuous efforts are important to consolidate an epidemiological surveillance of the main respiratory viruses affecting children. This study represents the first information of the state of Minas Gerais.

\section{ACKNOWLEDGMENTS}

To Dr Dean D Erdman, Respiratory and Enteric Viruses Branch of Centers for Disease Control and Prevention (CDC), Atlanta, GA, and Prof. Dr Eurico Arruda Neto, Faculdade de Medicina de Ribeirão Preto, Universidade de São Paulo, Brazil, for providing reagents. To the laboratories of Immunology, Parasitology, Molecular Biology, Physiology, and Genetics, UFU, for their equipments. To the health care professionals of the Hospital de Clínicas, as well as the group of Laboratory of Climatology/Instituto de Geografia, UFU, for their important contributions.

\section{REFERENCES}

Arruda E, Hayden FG 1993. Detection of human rhinovirus RNA in nasal washings by PCR. Mol Cell Probes 7: 373379.

Arruda E, Hayden FG, McAuliffe JF, Sousa MA, Mota SB, Mcauliffe MI, Geist FC, Carvalho EP, Fernandes MC, Guerrant RL, Gwaltney Jr JM 1991. Acute respiratory viral infections in ambulatory children of urban northeast Brazil. J Infect Dis 164: 252-258.

Ayres M, Ayres Jr M, Ayres DL, Santos AAS 2003. BioEstat Aplicações Estatísticas nas Áreas das Ciências Bio-médicas, Versão 3.0, Belém, Pará, Brasil.

Barrera CA, Reyes-Terán 2005. Influenza: forecast for a pandemic. Arch Med Res 36: 628-636.

Benten IJ van, Drunen CM van, Koopman LP, Middelkoop BC van, Hop WCJ, Osterhaus ADME, Neijens HJ, Fokkens WJ 2005. Age- and infection-related maturation of the nasal immune response in 0-2-year-old children. Allergy 60: 226-232.
Bosso PAR, Candeias JMG, Paduan KS, Ricchetti SMQ, Miranda AFM, Rugolo LMSS, Durigon EL, Ventura AM 2004. Human respiratory syncytial virus detection in children admitted at a community hospital in Botucatu, SP, Brazil. Braz J Microbiol 35: 348-351.

Calegari T, Queiróz DAO, Yokosawa J, Silveira HL, Costa LF, Oliveira TFM, Luiz LN, Oliveira RC, Diniz FC, Rossi LMG, Carvalho CJ, Lima AC, Mantese OC 2005. Clinical-epidemiological evaluation of respiratory syncytial virus in children attended in a public hospital in Midwestern Brazil. Braz J Infect Dis 9: 154-159.

Checon RE, Siqueira MM, Lugon AK, Portes S, Dietze R 2002. Seasonal pattern of respiratory syncytial virus in a region with a tropical climate in southeast Brazil. Am J Trop Med Hyg 67: 490-491.

Cintra OAL, Owa MA, Machado AA, Cervi MC, Figueiredo LTM, Rocha GM, Siqueira MM, Arruda E 2001. Occurrence and severity of infections caused by subgroup A and B respiratory syncytial virus in children in southeast Brazil. J Med Virol 65: 408-412.

Cox NJ, Tamblyn SE, Tam T 2003. Influenza pandemic planning. Vaccine 21: 1801-1803.

Crowe Jr JE 2001. Influence of maternal antibodies on neonatal immunization against respiratory virus. Clin Infect Dis 33: 1720-1727.

Ellis JS, Zambon MC 2002. Molecular diagnosis of influenza. Rev Med Virol 12: 375-389.

Erhart LM, Rangel MC, Lu Peng-Jun, Singleton JA 2004. Prevalence and characteristics of children at increased risk for complications from influenza, United States, 2000. J Pediatr 144: 191-195.

Glezen WP, Paredes A, Allison JE, Taber LH, Frank AL 1981. Risk of respiratory syncytial virus infection for infants from low-income families in relationship to age, sex, ethnic group, and maternal antibody level. J Pediatr 98: 708-715.

Hayden FG 2004. Rhinovirus and the lower respiratory tract. Rev Med Virol 14: 17-31.

Heikkinen T, Jãrvinen A 2003. The common cold. Lancet 361: 51-59.

Heikkinen T, Silvennoinen H, Reunanen T, Ziegler T, Vainionpää $\mathrm{R}$ 2004. Illness symptoms and absences due to influenza in different age groups of children. International Congress Series 1263: 101-104.

Hoogen BG van den, Jong JC, Groen J, Kuiken T, Groot R, Fouchier RAM, Osterhaus DME 2001. A newly discovered human metapneumovirus isolated form young children with respiratory tract disease. Nat Med 7: 719-724.

Kotaniemi-Syrjänen A, Vainionpää R, Reijonen TM, Waris M, Korhonen K, Korppi M 2003. Rhinovirus-induced wheezing in infancy - the first sign of childhood asthma? J Allergy Clin Immunol 111: 6671.

Kuiken T, Fouchier R, Rimmelzwaan G, Osterhaus A 2003. Emerging viral infections in a rapidly changing world. Curr Opin Biotechnol 14: 641-646.

Lemanske Jr RF, Jackson DJ, Gangnon RE, Evans MD, Li Z, Shult PA, Kirk CJ, Reisdorf E, Roberg KA, Anderson EL, Carlson-Dakes KT, Adler KJ, Gilbertson-White S, Pappas TE, DaSilva DF, Tisler CJ, Gern JE 2005. Rhinovirus ill- 
nesses during infancy predict subsequent childhood wheezing. J Allergy Clin Immunol 116: 571-577.

Malcolm E, Arruda E, Hayden FG, Kaiser L 2001. Clinical features of patients with acute respiratory illness and rhinovirus in their bronchoalveolar lavages. J Clin Virol 112: 9-16.

Miyao CR, Gilio AE, Vieira S, Hein N, Pahl MM C, Betta SL, Durigon EL, Stewien KE, Queiróz DAO, Botosso VF, Gomes MCS, Lopes CLBC, Ejzenberg B, Okay Y 1999. Infecções virais em crianças internadas por doença aguda do trato respiratório inferior. J Pediatr 75: 334-344.

Monobe H, Ishibashi T, Nomura Y, Shinogami M, Yano J 2003. Role of respiratory viruses in children with acute otitis media. Int J Pediatr Otorhinolaryngol 67: 801-806.

Monto AS 2002. Epidemiology of viral respiratory infections. Am J Med 112: 4S-12S.

Monto AS, Fendrick N, Sarnes MW 2001. Respiratory illness caused by picornavirus infection: a review of clinical outcomes. Clin Ther 23: 1615-1627.

Moura FEA, Borges LC, Portes SAR, Ramos EAG, Siqueira MM 2003. Respiratory syncytial virus infections during an epidemic period in Salvador, Brazil. Viral antigenic group analysis and description of clinical and epidemiological aspects. Mem Inst Oswaldo Cruz 98: 739-743.

Nascimento JP, Siqueira MM, Sutmoller F, Krawczuk MM, Farias V, Ferreira V, Rodrigues MJ 1991. Longitudinal study of acute respiratory diseases in Rio de Janeiro: occurrence of respiratory viruses during four consecutive years. Rev Inst Med Trop São Paulo 33: 287-296.

Neuzil KM, Zhu Y, Griffin MR, Edwards KM, Thompson JM, Tolleffson SJ, Wright PF 2002. Burden of interpandemic influenza in children younger than 5 years: a 25 -year prospective study. J Infect Dis 185: 147-152.

Papadopoulos NG, Moustaki M, Tsolia M, Bossios A, Astra E, Prezerakou A, Gourgiotis D, Kafetzis D 2002. Association of rhinovirus infection with increased disease severity in acute bronchiolitis. Am J Respir Crit Care Med 165: 12851289.

Piedimonte G 2001. Neural mechanisms of respiratory syncytial virus-induced inflammation and prevention of respira- tory syncytial virus sequelae. Am J Respir Crit Care Med 163: S18-S21.

Queiróz DAO, Durigon EL, Botoso VF, Ejzemberg B, Vieira SE, Mineo JR, Yamashita C, Hein N, Lopes CL, Cacharo AL, Stewien KE 2002. Immune response to respiratory syncytial virus in young brazilian children. Braz J Med Biol Res 35: 1183-1193.

Savolainen C, Blomqvist S, Hovi T 2003. Human rhinoviruses. Paediatr Respir Rev 4: 91-98.

Souza LSF, Ramos EAG, Carvalho FM, Guedes VMCR, Souza LS, Rocha CM, Soares AB, Velloso LF, Macedo IS, Moura FEA, Siqueira M, Fortes S, Jesus CC, Santiago CMG, Carvalho AMS, Arruda E 2003. Viral respiratory infections in young children attending day care in urban northeast Brazil. Pediatr Pulmonol 35: 184-191.

Straliotto SM, Nestor SM, Siqueira MM 2001. Respiratory syncytial virus groups A and B in Porto Alegre, Brazil, from 1990 to 1995 and 1998. Mem Inst Oswaldo Cruz 96: 155-158.

Tan WC, Xiang X, Qiu D, Ng TP, Lam SF, Hegele RG 2003. Epidemiology of respiratory viruses in patients hospitalized with near-fatal asthma, acute exacerbations of asthma, or chronic obstructive pulmonary disease. Am J Med 115: 272-277.

Tsuchiya LRRV, Costa LMD, Raboni SM, Nogueira MB, Pereira LA, Rotta I, Takahashi GRA, Coelho M, Siqueira MM 2005. Viral respiratory infection in Curitiba, Southern Brazil. J Infect 51: 401-407.

Vieira SE, Stewien KE, Queiróz DAO, Durigon EL, Torok TJ, Anderson LJ, Miyao CR, Hein N, Botosso VF, Pahl MM, Gilio AE, Ejzenberg B, Okay Y 2001. Clinical patterns and seasonal trends in respiratory syncytial virus hospitalizations in São Paulo, Brazil. Rev Inst Med Trop São Paulo 43: 125-131.

Williams B G, Gouws E, Boschi-Pinto C, Bryce J, Dye C 2002. Estimates of world-wide distribution of child deaths from acute respiratory infections. Lancet Infect Dis 2: 25-32.

Zamorano A, Márquez S, Aránguiz JL, Bedregal P, Sánchez I 2003. Relación entre bronquiolitis aguda con factores climáticos y contaminación ambiental. Rev Méd Chile 131: 1117-1122. 